\title{
The making of ESSKA: from an organization to an institution
}

\author{
Romain Seil ${ }^{1,2,3}$
}

Published online: 2 June 2016

(C) European Society of Sports Traumatology, Knee Surgery, Arthroscopy (ESSKA) 2016

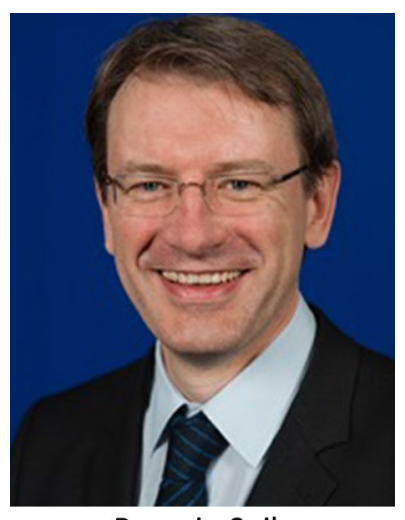

Romain Seil

ESSKA is a truly European project. I grasped this idea, and was profoundly affected by its spirit, at Nice in 1998, my first ESSKA congress. Never before had I attended a meeting where I'd felt this European 'unity in diversity', over and above the medical interests. I come from Luxembourg, one of the smallest countries on Earth, shaken by our neighbours over the centuries, and having to harmonize with different cultures and languages. Internationalism must be in our genes, and that's probably why I fell in love with ESSKA.

Romain Seil

rseil@yahoo.com

1 European Society of Sports Traumatology, Knee Surgery and Arthroscopy (ESSKA), Luxembourg, Luxembourg

2 Centre Hospitalier de Luxembourg - Clinique d' Eich, 78, rue d Eich, 1460 Luxembourg, Luxembourg

3 Sports Medicine Research Laboratory, Luxembourg Institute of Health (LIH), 78 rue d'Eich, 1460 Luxembourg, Luxembourg
In the following years, I did my academic homework. I published in KSSTA, gave presentations at ESSKA congresses, and participated in other scientific societies, both national and international. But the definitive event for me, professionally, was my selection for ESSKA-AOSSM Travelling Fellowship in 2001. The following year, and under the auspices of my fellowship-godfather Pierre Chambat, I found myself literally projected onto ESSKA's Board!

As ESSKA's General Secretary, and still a young orthopaedic surgeon, I was brought into close contact with ESSKA's leaders and respective presidents. These men were true leaders, in fields where true leadership was needed. They were more than good surgeons and scientists; they were also communicators, diplomats and managers, negotiators, analysts, and inspirers. They taught me how an international medical society like ESSKA should function, and gave me the privilege of helping in shaping its future. In those days, ESSKA was already esteemed in Europe and beyond, although still a small society of few hundred. The work was mostly done by the President in his home office, the journal was run in Sweden by Ejnar Eriksson, and that was basically it.

Fourteen years later, our scientific backbone remains unchanged. We still have our biannual congress, the KSSTA journal, and various fellowships (of which the European-North American exchange is the oldest). But so many things have changed around it. In 2005, I hired our first professional staff member in Luxembourg and negotiated an office for ESSKA within my hospital; in 2010, we held the first Strategic Leadership meeting in Amsterdam; in 2012, we hired our first executive director, Zhanna Kovalchuk; and in 2013, we inaugurated ESSKA's Foundation. We have more than tripled our active membership over the last 8 years, and now have over 3000 active members. Coming from more than 100 countries, with one-third outside of Europe, this generates a modest global footprint. 
ESSKA has now consolidated. We have an efficient and professional office of 8 specialists. The Board has been enlarged from 5 to 13 . Our clinical journal 'Knee Surgery Sports Traumatology and Arthroscopy' (KSSTA) is now owned by the society, ranks among the top ten journals worldwide for orthopaedics and sports medicine, and has an impact factor of 3.05 (up from 1.6 in 2008). Our open-access basic science 'Journal of Experimental Orthopaedics' (JEO) has just been accepted by MEDLINE. Our online education portal 'ESSKA Academy' has an increasing number of visitors after we decided to open much of its content to the general public. Our book programme, in only a few years, has generated a comprehensive ESSKA library. Our sections and committees now actively support these various means of communication and publication, and our surgical courses and fellowship programmes are increasingly structured to the same end, with Annual Fellowships offering nearly 50 places. Our Meniscus Consensus Group is Europe's first consensus initiative, according to a strict methodology. Thirty-four subspecialized national societies chose to join our affiliation programme. And, finally, the ESSKA Foundation is beginning to generate enthusiasm, with the very successful 'Cycle for Science' project, the paediatric ACL monitoring initiative, and by helping poorer countries with their arthroscopy, sports traumatology, and knee surgery. An immediate benefit of the project's fund-raising will be an Instructional Course Lecture Book, which will be distributed to all ESSKA members at the next congress in Glasgow in 2018.

But there is much more to do. We need to accommodate the two new committees on hip arthroscopy and osteotomy, the new interdisciplinary sports medicine section ESMA, and generally to refine the work of the sections. Although ESSKA is nearly 35 years old, we are still pioneers in some parts of Europe. It is a great pleasure to observe many national societies being formed in former communist countries from Eastern Europe, and then seeking affiliation with
ESSKA. This will spread a new web of collaboration, networking, and friendship across our continent. It is our role to promote this exchange in every possible way.

All these achievements would not have been possible without the dedication, the leadership, the idealism, and creativity of a small number of individuals. Over the years, our board and the staff have managed to generate a remarkable-I would say an infectious-enthusiasm, as well as a high level of organization, so essential for a modern scientific society. This enthusiasm has spread outwards, to KSSTA's editorial group under the leadership of Jon Karlsson, to the other publication teams, the working committees, and sections. Altogether, nearly 200 people participate in these activities, the vast majority as volunteers. Apart from this, we have our tried-and-tested institutional partners: the medical industry, which we increasingly consider as our partners for various projects; Intercongress, the guarantor of quality for our congress; SpringerNature, our publisher for journals and books; MultiLearning, our partner for online education, the Fondation de Luxembourg, which hosts our Foundation, etc. Without this active involvement of many members and partners, ESSKA would not be what it is today: the leading society in knee surgery, sports traumatology, and arthroscopy for Europe.

I could not have dreamt of a better moment to be granted the Presidency of such a splendid society. And I don't intend to rest on its laurels. I shall make every effort to take ESSKA to the next level. If we are to follow the path of success, we need to continue the hard work that has brought us so far. It will be my role as ESSKA's president to coordinate the various teams, keep the volunteers together, and ensure a well-structured, welcoming, and productive environment. This will benefit ESSKA, it will benefit Europe, and it will benefit our patients.

I have inherited an organization, but I hope to bequeath to an institution. 